Check for updates

Cite this: Phys. Chem. Chem. Phys., 2020, 22, 6826

Received 24th January 2020, Accepted 5th March 2020

DOI: $10.1039 / \mathrm{d} 0 \mathrm{cp} 00402 \mathrm{~b}$

rsc.li/pccp

\section{Unwanted effects of X-rays in surface grafted copper(II) organometallics and copper exchanged zeolites, how they manifest, and what can be done about them $\dagger$}

\author{
Mark A. Newton, (D) *a Amy J. Knorpp, ${ }^{a}$ Jordan Meyet, $^{a}$ Dragos Stoian, ${ }^{b}$ \\ Maarten Nachtegaal, ${ }^{c}$ Adam H. Clark, (D) ${ }^{c}$ Olga V. Safonova, (D) ${ }^{c}$ Hermann Emerich, ${ }^{b}$ \\ Wouter van Beek, ${ }^{\text {b }}$ Vitaly L. Sushkevich (D) ${ }^{d}$ and Jeroen A. van Bokhoven (iD *ad
}

\begin{abstract}
Copper(II) containing materials are widely studied for a very diverse array of applications from biology, through catalysis, to many other materials chemistry based applications. We show that, for grafted copper compounds at the surface of silica, and for the study of the selective conversion of methane to methanol using copper ion-exchanged zeolites, the application of focused X-ray beams for spectroscopic investigations is subject to significant challenges. We demonstrate how unwanted effects due to the X-rays manifest, which can prevent the study of certain types of reactive systems, and/or lead to the derivation of results that are not at all representative of the behavior of the materials in question. With reference to identical studies conducted at a beamline that does not focus its X-rays, we then delineate how the total photon throughput and the brilliance of the applied $X$-rays affect the apparent behavior of copper in zeolites during the stepwise, high temperature and aerobic activation approach to the selective conversion of methane to methanol. We show that the use of increasingly brilliant X-ray sources for X-ray spectroscopy can bring with it significant caveats to obtaining valid and quantitative structure-reactivity relationships (QSARS) and kinetics for this class of material. Lastly, through a systematic study of these effects, we suggest ways to ensure that valuable allocations of $X$-ray beam time result in measurements that reflect the real nature of the chemistry under study and not that due to other, extraneous, factors
\end{abstract}

\section{Introduction}

The use of tunable synchrotron X-ray sources to understand the behavior of materials on a variety of length and time scales has become central to many scientific disciplines. The development of such sources, through what is now four generations of technological and scientific innovation, has resulted in increasingly diverse and powerful ways in which tunable, and ever more brilliant, X-rays may be used to advance our understanding of how materials of a multitude of types function. Of these methods, $\mathrm{X}$-ray spectroscopy is often the go-to technique to study chemical speciation in functional materials under operando, that is to say working, conditions. ${ }^{1}$ This is especially the case in classes of functional materials, wherein the degree of long-range order in

\footnotetext{
${ }^{a}$ Department of Chemical and Bioengineering, ETH Zurich, Zurich, Switzerland.

E-mail: mark.newton@chem.ethz.ch, jeroen.vanbokhoven@chem.ethz.ch

${ }^{b}$ Swiss Norwegian Beamlines (SNBL), Grenoble, Isere, France

${ }^{c} P S I$, SYN, Villigen, Switzerland

${ }^{d}$ Paul Scherrer Institut, Villigen, Switzerland

$\dagger$ Electronic supplementary information (ESI) available. See DOI: 10.1039/ d0cp00402b
}

the active components is not sufficient to permit access to elements of structure and structural change using methods based upon microscopy, X-ray scattering, or other laboratory-based spectroscopies and methods. The many variants of X-ray spectroscopy, made in transmission or fluorescence geometries, and often with high temporal and spatial resolution, offer unique and elementally specific windows into many aspects of reactivity and structure. ${ }^{1 a}$ These windows, and the data that can be derived from them, form the basis from which the QSARS may be derived and used as the foundations of rational design.

However, the utility of such methods is predicated upon an axiom that underpins any form of experimentation: that the observation of a system by any given method should not change that which is being observed to any significant degree. Therefore, as probes that can interact strongly with matter become more and more powerful, a proportionately increased awareness of the potential for these probes to affect the results derived from their use is warranted.

In the specific case of X-ray spectroscopy, developments that are ongoing at synchrotrons around the world are leading to the production of ever more brilliant X-ray sources. Furthermore, 
a trend for equipping more modern spectroscopy resources with a variety of collimating and focusing devices - most commonly toroidal focusing mirrors placed after the X-ray monochromator - has, in recent years, become commonplace, almost to the point of ubiquity. $\ddagger$ These advances lead to the possibility of new types of study; equally, however, increasing brilliance equates to an increased power density that the material under study must be able to withstand.

In certain areas of research, specifically macromolecular crystallography, ${ }^{2-10}$ a great deal of attention is paid to issues regarding the unwanted effects that X-rays might have on the information obtained from a given experiment. As a result, a great deal of work has been dedicated to understanding and quantifying the doses of X-rays that can be sustained before deleterious effects due to the X-rays themselves might invalidate any conclusions drawn from experiment. Indeed, and in specific reference to the study of copper containing enzymes, a variety of effects due to the X-rays have been identified including reduction of $\mathrm{Cu}^{\mathrm{II}}$ centres. ${ }^{7-11}$

In other important areas, such as material chemistry and heterogeneous catalysis, which largely occupy themselves with materials that are inorganic, rather than predominantly organic and biological in nature, such systematic studies of the radiation tolerances of materials are much less common. That said, studies do exist, ${ }^{11-19}$ that have reported, and to varying degrees examined, X-ray induced damage in a variety of systems, including those based upon $\mathrm{Cu}^{\mathrm{II}}$ in solution. ${ }^{13,19}$

The two types of copper-based material we consider are, to varying degrees, and amongst many other types inorganic materials, investigated to understand how to achieve speciation and process environment required for the efficient and selective conversion of methane to methanol. ${ }^{20-52}$ The desirability of achieving such a direct conversion is matched by the extreme challenge that this conversion poses to materials synthesis and process design. Methanol is much easier to oxidise than methane and this means that selective conversion of methane is subject to severe conversion/selectivity limitations. ${ }^{44,53-55}$

Copper containing zeolites have been the focus of much academic attention since the discovery in $2005^{21,22}$ that, when hosted in certain zeolites, some of the $\mathrm{Cu}^{\mathrm{II}}$ species that result from activation at elevated temperatures can successfully mediate the selective conversion of methane conversion. Subsequent research has

\footnotetext{
\$ We are currently aware of only a very few such resources (for example, in Europe) that are able to operate in the non-focused and low brilliance manner that was possible on BM $31,{ }^{56}$ and that we have demonstrated can be achieved at SuperXAS, ${ }^{57}$ though with very significant demagnification and attenuation of the $\mathrm{X}$-ray beam. These include the bending magnet spectroscopy lines at the ESRF (currently offline due to the upgrade of the ESRF lattice) and the XAFS beamline at Sincrotrone Trieste, Italy. ${ }^{70}$ However, SuperXAS at the SLS, ${ }^{57}$ along with virtually all spectroscopy lines capable of the sorts of experiments we have conducted in this study, (e.g. B18 (Diamond Light Source ${ }^{71}$ ), Rock and Samba (Soleil ${ }^{72,73}$ ), Balder (Max IV ${ }^{74}$ ), CLAESS ( Alba $^{75}$ ) and P64/P65 (Hamburg ${ }^{76,77}$ ) either utilize focusing elements, or are situated on insertion devices capable of delivering higher photon fluxes and densities than either SuperXAS, or BM31. We note, however, that in the case of P65, ${ }^{77}$ although situated on an undulator, this line is designed to yield relatively large beam spots $(1 \times 0.5 \mathrm{~mm})$ and uses no focusing elements.
}

resulted in great improvements in performance, and synchrotronbased X-ray absorption spectroscopy (XAS) has often been employed to elucidate aspects of how the $\mathrm{Cu}^{\mathrm{II}}$ species supported upon amorphous oxides, ${ }^{20}$ or contained within the microporous structure of the zeolites, $26,27,29,31,35,41,42,45-50,52$ facilitate the conversion of methane to methanol. Indeed, quantitative XAS measurements, when coupled to quantitative measures of reactivity, have formed the basis by which the fundamental processes underlying how this chemistry is mediated have been understood. ${ }^{47-50}$

Through carrying out the same experiments, made using the same equipment and samples, at two different X-ray spectroscopy beam lines, we have observed the unwanted phenomena that we now report. In this paper, therefore, we show that power densities that are typically applied to the study of functional materials on modern X-ray spectroscopy beamlines, can severely hamper the meaningful study of some types of materials. Through a subsequent systematic study of how X-ray brilliance and photon flux affect the apparent behavior of copper in zeolites during activation and reaction with methane, we then attempt to understand what action is required to be taken, such that meaningful X-ray spectroscopic data may be obtained.

\section{Experimental}

\section{Materials}

Two grafted $\mathrm{Cu}^{\mathrm{II}}$ systems have been utilised in this study referred to as $\mathrm{Cu}^{\mathrm{II}}(\mathrm{TMEDA}) @ \mathrm{Al}_{2} \mathrm{O}_{3}$ and $\mathrm{Cu}^{\mathrm{II}}(\mathrm{TMEDA}) @ \mathrm{SiO}_{2}$. These are derived from grafting of the parent $\left[\mathrm{Cu}\left(\mathrm{OSi}(\mathrm{O} t \mathrm{Bu})_{3}\right)_{2}(\mathrm{TMEDA})\right]$ molecule with (TMEDA) = tetramethylethylenediamine. Complete descriptions of the synthesis of the parent molecule, along with its grafting and subsequent characterization, can be found elsewhere. ${ }^{20}$

The $\mathrm{Cu} / \mathrm{MOR}$ material $(4.36 \mathrm{wt} \% \mathrm{Cu})$ used in this study is that based upon a commercial MOR (zeolyst, mordenite, CBV10A, $\mathrm{SiO}_{2} / \mathrm{Al}_{2} \mathrm{O}_{3}=13$, in sodium form) whose synthesis, characterization, and net performance under the conditions of high temperature activation in oxygen applied here have also been reported previously. ${ }^{41,45,46}$

\section{Overall experimental setup}

All experiments were carried out at either BM31 of the SwissNorwegian beamlines (SNBL) at the ESRF, ${ }^{56}$ or the SuperXAS beamline at SLS. ${ }^{57}$ BM31 is a bending magnet beamline that uses no focusing optics, and conditioning the X-ray beam for use is achieved only through the use of slits. SuperXAS is a beamline that utilises a "Superbend", a cryogenically cooled superconducting bending magnet, which yields higher magnetic fields (2.9 Tesla), and greater photon fluxes at higher energies, than a conventional bending magnet placed on the same X-ray source. At the $\mathrm{Cu}$ K-edge these configurations lead to BM31 delivering a flux of $c a .3 .6 \times 10^{9}$ photons $\mathrm{s}^{-1}$ whereas a

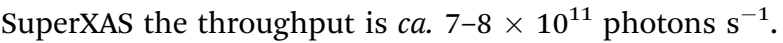

At SNBL, X-ray monochromator was achieved using a $\mathrm{Si}[111]$ double crystal monochromator configured for fast scanning that permitted collection of $\mathrm{Cu}$ K-edge X-ray absorption near edge structure (XANES) on zeolite samples every 17 seconds; in 
these transmission-based studies ion chambers were utilised for detection of the incoming and transmitted X-ray beams. For studies of the low loaded (typically $<0.5 \mathrm{wt} \%$ ) copper organometallics grafted upon silica or alumina supports, XAFS data was collected in fluorescence (using a silicon diode or multichannel germanium fluorescence detector) and transmission modes with individual extended X-ray absorption fine structure (EXAFS) scans of $c a .21$ minutes duration being continuously collected, inspected, and, as appropriate, subsequently averaged. At SNBL the unfocussed X-ray beam was shaped solely through the use of slits to give beam dimensions of 400-500 $\mu \mathrm{m}$ (vertical) and 3000-4000 $\mu \mathrm{m}$ (horizontal). As such, the brilliance of the X-rays used at SNBL was of the order of $1.8 \times 10^{9}$ photons $\mathrm{mm}^{-2} \mathrm{~s}^{-1}$. Subsequently, in the text and figures, SNBL is therefore referred to as the low brilliance source (LBS).

At the SuperXAS beamline, the same equipment, sample presentation, and detection methods were adopted. In this case, however, the beamline utilizes a fast scanning monochromator based upon rapid oscillation of a $\mathrm{Si}[111]$ channel cut crystal. ${ }^{57}$ This enables extremely rapid collection of XAS data for measurements made in transmission, that in the current case was used to give a quick-scanning extended X-ray absorption fine structure (QEXAFS) acquisition rate of $2 \mathrm{~Hz}$. For fluorescence measurements, which used a 5-element silicon drift detector, data were acquired using a step-wise (in energy) mode of collection that yielded a single EXAFS scan in $c a .40$ minutes of X-ray exposure.

SuperXAS utilizes a toroidal mirror to focus the X-rays to a spot size of $c a .80 \times 80 \mu^{2}$. To study the effects of X-ray brilliance on the behavior the samples the toroid was manipulated, to yield three specific foci: $80 \times 80 \mu \mathrm{m}^{2} ; 700 \times 50 \mu \mathrm{m}^{2}$; and $2000 \times 150 \mu \mathrm{m}^{2}$; these foci bring with them associated brilliances of the order of, $1.2 \times 10^{14}, 2-3 \times 10^{13}$, and 1.9-2.5 $\times$ $10^{12}$ photons $\mathrm{mm}^{-2} \mathrm{~s}^{-1}$. Henceforth, therefore, SuperXAS will be referred to as the high brilliance source (HBS).

To investigate the effects of total photon throughput, the $\mathrm{X}$-ray beam was also moderated using vitreous carbon attenuators of 2 and $5 \mathrm{~mm}$ thickness that, at $9 \mathrm{keV}$, result in reductions in photon throughput of $74 \%$ and $97 \%$ respectively. ${ }^{58}$ The second of these attenuators, combined with the largest beam spot used at SuperXAS $\left(2000 \times 150 \mu^{2}\right)$, yields a brilliance of ca. $7 \times 10^{10}$ photons $\mathrm{mm}^{-2} \mathrm{~s}^{-1}$ at the sample.

\section{Sample presentation and reaction protocols}

1. Surface-grafted copper(II) systems. The samples generated from the grafting of copper organometallic species to either silica or alumina, ${ }^{20}$ require handling and presentation in the absolute absence of moisture and oxygen. These samples were loaded into capillaries ( $1 \mathrm{~mm}$ i.d.) and sealed inside a glove box. The sealed capillaries were then mounted onto a sample changer and investigated using both transmission and fluorescence yield EXAFS. At SuperXAS the use of cryogenic cooling was also, eventually, employed (vide infra).

2. In situ and kinetic studies of the activation and reaction with methane of copper in zeolites. On both beamlines, $c a .10 \mathrm{mg}$ of sieved $(75 \mu \mathrm{m}<$ fraction $<106 \mu \mathrm{m}) \mathrm{Cu} / \mathrm{MOR}$ sample was presented as a packed bed (ca. $5 \mathrm{~mm}$ in length) secured using quartz wool plugs within a $2 \mathrm{~mm}$ i.d. (o.d. $=2.2 \mathrm{~mm}$ ) capillary. The sample was then mounted within a reactor system based on the design due to Chupas et al. ${ }^{59}$ that we have demonstrated ${ }^{60}$ to yield an isothermal region twice the length of the sample bed and, therefore, to be appropriate to the kinetic study of these materials. All gases were of a high purity and flowed through scrubbers, as appropriate for each gas, to remove any residual oxygen and moisture prior their being passed through mass flow controllers (20 $\mathrm{ml} \mathrm{min}^{-1}$ all gases). Three, remotely operated, Valco (VICI) fourport switching valves were used to select the three different gas flows (argon, oxygen, and methane) required for experimentation. A mass spectrometer (Pfeiffer) was used to establish the net levels of purity of each gas flow arrived at and that no leaks in the system were present.

The sample was heated under $20 \mathrm{ml} \mathrm{min}{ }^{-1}$ oxygen at $10 \mathrm{~K} \mathrm{~min}^{-1}$ to $723 \mathrm{~K}$. At this point copper K-edge XANES spectra were recorded. The sample was then cooled $\left(60 \mathrm{~K} \mathrm{~min}^{-1}\right)$ to the temperature required for subsequent reaction in methane (403-493 K) whereupon XANES of the activated sample was collected again. The gas flow was briefly switched from oxygen to argon before methane was subsequently switched into the reactor. At this point the development of the system was monitored using $\mathrm{Cu}$ K-edge XANES (spectral repetition rate of one spectrum every 17 seconds) spectrum at SNBL, 2 spectra per second, bi-directional collection at SuperXAS, and online MS for $c a .3000$ seconds. The sample was placed briefly under argon again before again admitting a flow of oxygen, at which point the sample was reactivated by heating $\left(10 \mathrm{~K} \mathrm{~min}^{-1}\right)$ to $723 \mathrm{~K}$ before the process was repeated.

3. Data processing and analysis. The resulting XAFS data, collected at BM31 and during fluorescence measurements at SuperXAS, were reduced and normalized using the Prestopronto package ${ }^{61}$ that was also subsequently used to perform linear combination analyses using internally derived standards as has been previously documented. ${ }^{47-49}$

The QEXAFS data acquired in transmission mode at SuperXAS were processed using an in-house developed python program. ${ }^{62}$ Energy calibration was performed using the maximum derivative for a $\mathrm{Cu}$ foil mounted downstream from the sample. To reduce data point density due to the significant oversampling of angular data at SuperXAS a radial basis function interpolation was employed: a constant energy step of $0.1 \mathrm{eV}$ and a constant $k$ step of $0.025 \AA^{-1}$ was chosen for the XANES and EXAFS regions respectively. Linear combination analysis was performed, as previous, using Prestopronto. ${ }^{61}$

\section{Results}

1. Comparison of the behavior of surface grafted copper organometallics under X-ray illumination and the reaction of methane with activated $\mathrm{Cu}^{\text {II }}$ contained within mordenite ( $\left.\mathrm{Cu} / \mathrm{MOR}\right)$

Fig. 1 compares $\mathrm{Cu}$ K-edge XAFS spectra for a surface grafted copper organometallic system ( $\mathrm{Cu}^{\mathrm{II}}$ (TMEDA)@ $\mathrm{Al}_{2} \mathrm{O}_{3}$, see inset to Fig. 1) when measured (in fluorescence) on the HBS (red) and LBS (black and blue). 
It is immediately evident that the copper speciation is a function of both the beamline used and the duration of the measurement. As synthesised, and characterised by other methods, ${ }^{20}$ the grafting of the starting complex results in the generation of isolated $\mathrm{Cu}^{\mathrm{II}}$ sites. When measured at the LBS, this is clearly seen to be the case (blue spectrum), and whilst there is some evidence for a low level of degradation over time, in the form of a nascent pre-edge $\left(\mathrm{Cu}^{\mathrm{I}}\right)$ feature, black spectrum after $c a$. 5 hours of X-ray exposure, the majority character of the XANES envelope remains essentially intact. At the HBS, however, a very different story emerges: within a single fluorescence scan of $c a .40$ minutes duration, and (implicitly) on a timescale considerably less than that required to collect the entire EXAFS spectrum, the XANES indicates that a very significant fraction of the copper is already in the reduced $\mathrm{Cu}^{\mathrm{I}}$ state. Exposure of this material to the focused X-rays of the HBS therefore leads to a rapid degradation of the material that occurs within the time required to achieve a complete EXAFS scan. On the other hand, the non-focused LBS permits successive EXAFS scans to be achieved over several hours and with only minimal alteration to the observed copper speciation.

Fig. 2 shows the influence of measurement temperature on the $\mathrm{Cu}$ K-edge XANES for another surface grafted organometallic system ( $\left.\mathrm{Cu}^{\mathrm{II}}(\mathrm{TMEDA}) @ \mathrm{SiO}_{2}\right)$. In this transmission mode experiment the XANES was obtained rapidly $(2 \mathrm{~Hz})$ in transmission and the evolution of the XANES followed in time. As before, the results are compared to that achieved using measurement at ambient temperature at the LBS.

Once again, the $\mathrm{Cu}^{\mathrm{II}}$ speciation inherent to this organometallic is maintained when using the LBS, whereas exposure to the focused X-ray beam at the HBS results in immediate and rapid (Fig. 2(b)) degradation of the starting species. Moreover, Fig. 2(b) also shows that attempting to ameliorate this situation using cryogenics fails, and does not result in any significant stabilization of the $\mathrm{Cu}^{\mathrm{II}}$ under the influence of the focused X-ray beam. The sample remains therefore, essentially unmeasurable using a (nominally standard) optical setup; even at $t=0$ (i.e. the first scan), $\mathrm{Cu}^{\mathrm{I}}$, which the LBS measurement shows is not native to this sample, is found to be present in significant amounts.

As stated previously, these samples are intrinsically labile, and react rapidly with any moisture or oxygen. As such, a sensitivity of the $\mathrm{Cu}^{\mathrm{II}}$ centres native to these samples to other factors, such as local heating or electron-induced damage, might well be expected. However, it is evident that the use of a low brilliance X-ray beam does permit these samples to be interrogated in a useful manner, whereas the de facto standard operational setup the HBS does not.

Fig. 3 then show results obtained for the second class of materials we have studied, copper ion exchanged zeolites, on both LBS and $\mathrm{HBS}$, and specifically for $\mathrm{Cu} /$ mordenite $(\mathrm{Cu} / \mathrm{MOR})$; a system that has been much studied using XAS and in relation to the selective conversion of methane to methanol. ${ }^{26,29,31,35,41,45,46,48,50,52}$ Exemplary spectra from each study, along with a further zeolitic case, $\mathrm{Cu} /$ mazzite, which has been also shown to be active and highly selective for this conversion, ${ }^{49}$ are given as ESI. $\dagger$

The objective of these experiments is to understand the extent and the kinetics of the reaction of activated $\mathrm{Cu}^{\mathrm{II}}$ in the $\mathrm{Cu} / \mathrm{MOR}$ with methane. Fig. 3 gives the results of a twocomponent LCA analysis of XAS data obtained at (a) $413 \mathrm{~K}$ and (b) $453 \mathrm{~K}$. The LCA analysis utilizes standards, for dehydrated $\mathrm{Cu}^{\mathrm{II}}$ and $\mathrm{Cu}^{\mathrm{I}}$ species, that were derived internally from the system under study at each beamline. ${ }^{47-49}$ Once more, identical experiments, conducted at the two X-ray spectroscopy beamlines, yield radically different results, both in terms of the extent of the formation of $\mathrm{Cu}^{\mathrm{I}}$ at the two temperatures given, and in the kinetics of how this $\mathrm{Cu}^{\mathrm{I}}$ is formed under reaction conditions. As ESI, $\dagger$ we give a similar plot derived from experimentation using $\mathrm{Cu} / \mathrm{MAZ}$ rather than $\mathrm{MOR}$, wherein the same effects are compared between beamlines.

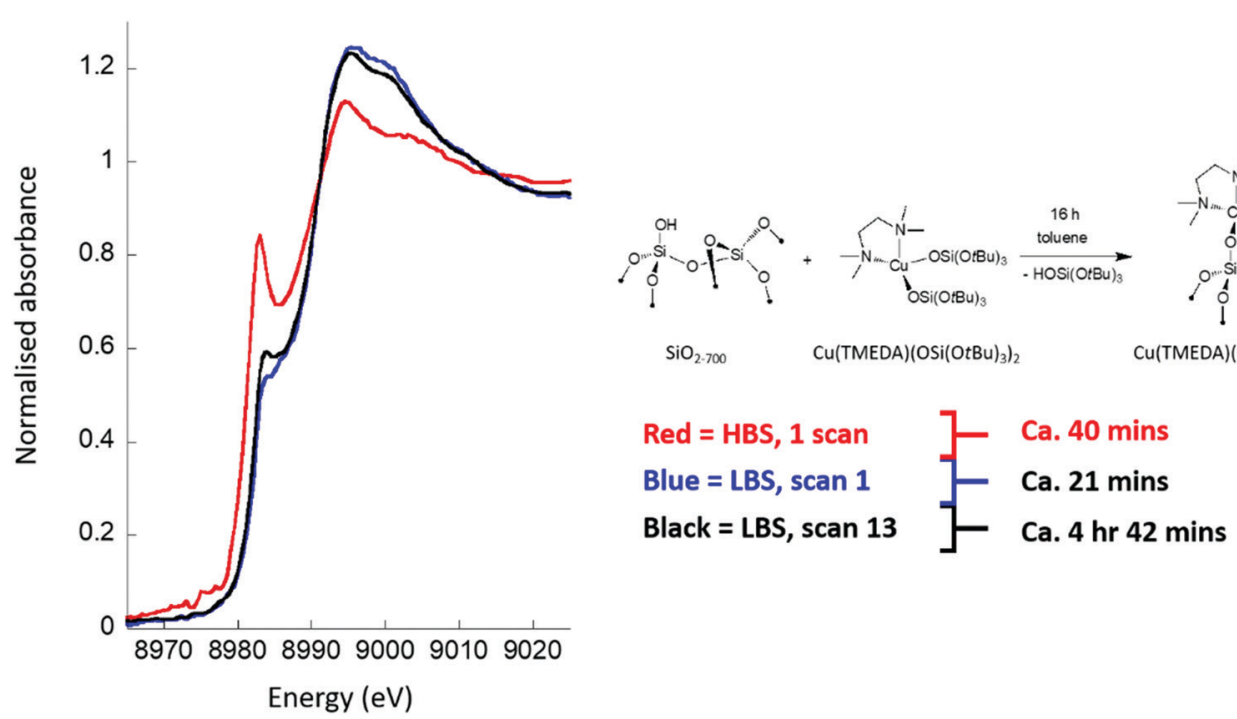

Fig. 1 Cu K-edge XANES illustrating how fluorescence yield XAFS reports upon the nature of copper speciation for a grafted Cu" organometallic species $\left(\mathrm{Cu}^{\prime \prime}(\mathrm{TMEDA})\left(\mathrm{aAl}_{2} \mathrm{O}_{3}\right)\right.$ over the time scales indicated, and for measurement on both the HBS (red) and LBS (black and blue). The sharp pre-edge feature observed at the HBS (red) spectrum pertains to the presence of higher levels of $\mathrm{Cu}^{\prime}$. 
(a)

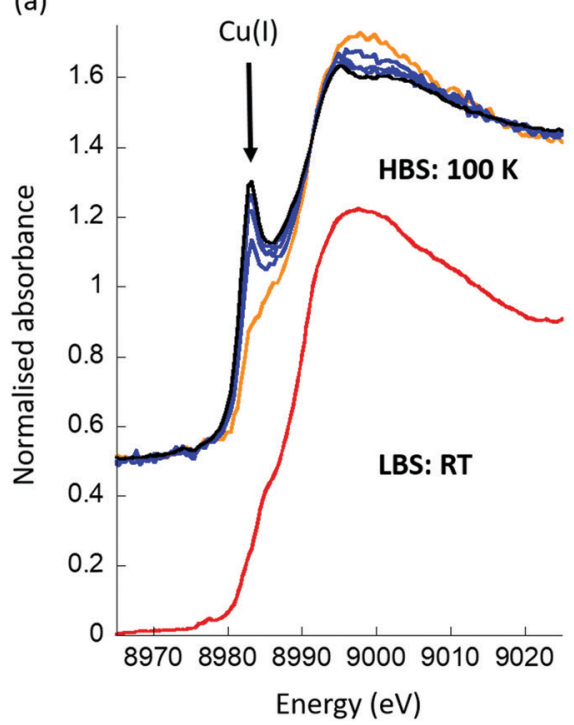

(b)

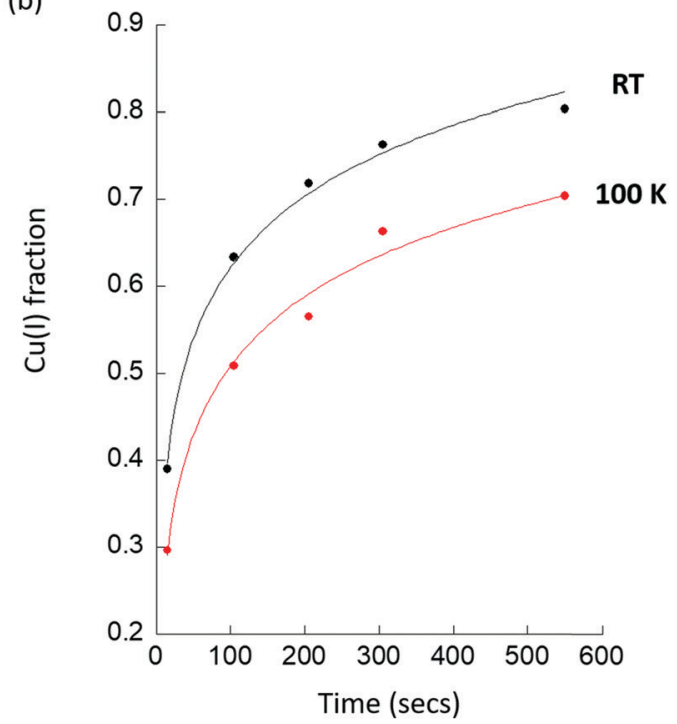

Fig. 2 (a) Comparison of the behavior of a surface grafted $\mathrm{Cu}^{\prime \prime}$ organometallic species ((Cu"(TMEDA)@SiO 2$)$ ), measured at the LBS (single EXAFS scan of ca. $21 \mathrm{~min}$ ) and HBS (as indicated and using a spectral repetition rate of $2 \mathrm{~Hz}$ averaged over 20 spectra) and using standard optical setups. The orange HBS spectrum corresponds to an average over the first 20 seconds to X-ray exposure; the black spectrum that obtained after ca. 550 seconds; the blue, intermediate spectra (b) time dependent evolution of $\mathrm{Cu}^{\prime}$ for this material obtained from the HBS at ambient temperature and at $100 \mathrm{~K}$ as indicated. Logarithmic fits (red and black lines) to the data are also given.
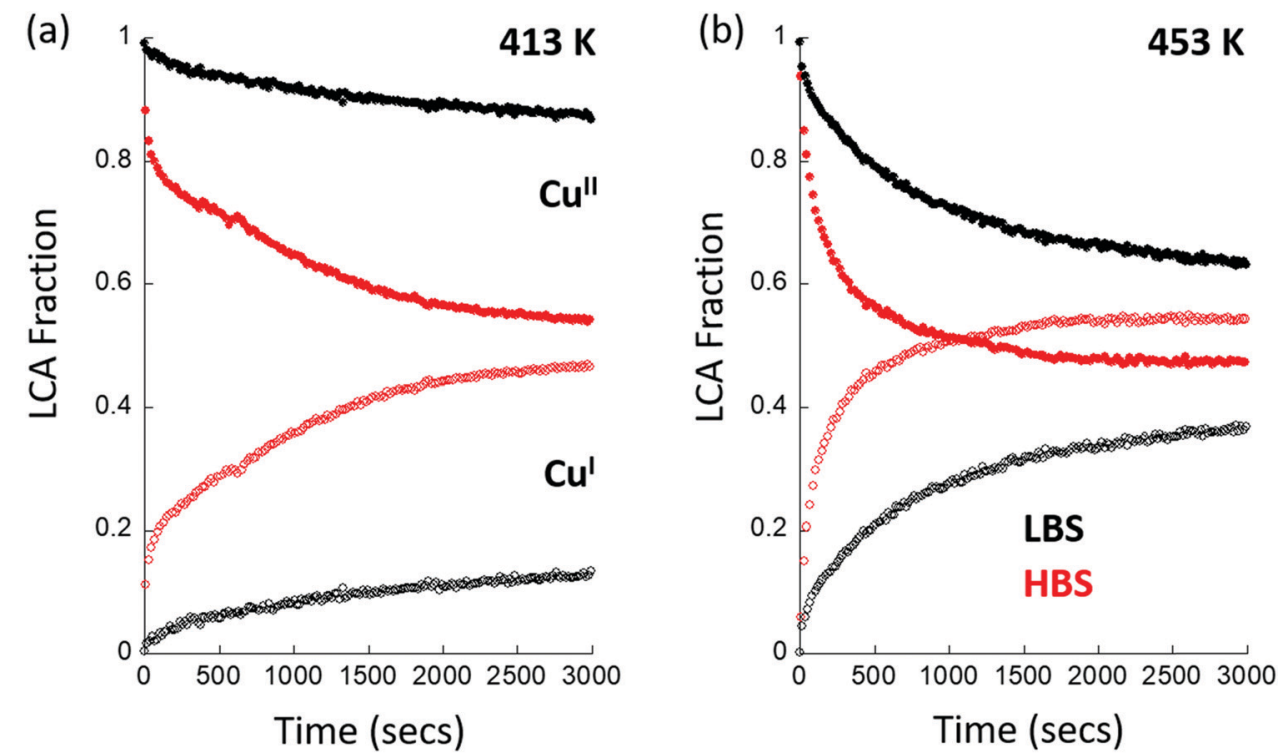

Fig. 3 Reaction of activated Cu/MOR with methane at two temperatures, 413, and $453 \mathrm{~K}$, as derived from LCA analysis of time resolved Cu K-edge XANES experiments conducted at, the LBS (black symbols) and HBS (red symbols) indicating relative fractions of $\mathrm{Cu}^{\prime \prime}$ (filled symbols) and $\mathrm{Cu}$ ' (open symbols). At the LBS a non-focused X-ray beam of ca. $4000 \times 500 \mu \mathrm{m}^{2}$ was employed; at the HBS an unattenuated and focused X-ray beam of close to ca. $80 \times 80 \mu \mathrm{m}^{2}$ was used.

Firstly, we find that, when using the HBS, that $\mathrm{Cu}^{\mathrm{I}}$ is already present in the material at $t=0$, whereas it is not when the same measurement is conducted at the LBS. Ordinarily, such an observation could be ascribed to auto-reduction of the copper, a phenomenon that has been often observed in such systems, and that can occur in the absence of X-rays. ${ }^{63-69}$ The head to head comparison, however, establishes that this is not an inherent property of this system. Instead, the initial presence of $\mathrm{Cu}^{\mathrm{I}}$ is a direct result of the application of the focused X-ray beam and the environment that the sample is experiencing. For example, no trace of $\mathrm{Cu}^{\mathrm{I}}$ is found under an oxygen atmosphere at 413 or $453 \mathrm{~K}$ after activation at $723 \mathrm{~K}$. However, as a direct switch between an oxygen flow and one of methane at elevated temperature is decidedly ill-advised, a transient purge with an inert gas (in this case argon) is required to be made. The presence of $\mathrm{Cu}^{\mathrm{I}} @ t=0$ in the methane switching experiment 
therefore means that, even under the "inert" purge, some fraction of the copper present is reduced by the X-rays, and the starting point for the experiment using methane has been proportionately compromised at the HBS, whereas it has not at the LBS. (Examples of the time dependence of the formation of $\mathrm{Cu}^{\mathrm{I}}$ for two cases at the HBS are given as ESI. $\dagger$ )

Secondly, we observe that at $t>0$, the rates at which $\mathrm{Cu}^{\mathrm{II}}$ is lost and $\mathrm{Cu}^{\mathrm{I}}$ appears are much greater at the HBS than at the LBS, and that the overall extent of reaction achieved by the end of the experiment $(t=3000 \mathrm{~s})$ is much greater on the former line as compared to the latter. Lastly, from the types of data shown in Fig. 3, an Arrhenius plot - based upon an assessment of the initial rates of $\mathrm{Cu}^{\mathrm{II}}$ consumption or $\mathrm{Cu}^{\mathrm{I}}$ evolution observed - to compare the apparent kinetics of the reaction with methane in the two sets of experiments, can be derived and is given as Fig. 4 .

The apparent activation energy $\left(E_{\text {app}}\right)$ for the reaction of methane with activated $\mathrm{Cu} / \mathrm{MOR}$ appears a factor $c a .3$ smaller at the HBS compared to the LBS. Moreover, the results from the LBS can be compared favorably to previous assessments of the reactivity of $\mathrm{Cu} / \mathrm{MOR}$ in the presence of methane using UV-vis. ${ }^{23,24}$ Once the different sensitivities toward the active $\mathrm{Cu}^{\mathrm{II}}$ speciation of XANES and UV-vis are taken into account, and it is recognised that transmission $\mathrm{Cu} \mathrm{K}$-edge XANES cannot discriminate between the two active $\mathrm{Cu}^{\mathrm{II}}$ species observed in UV-vis, the average $\left(54 \mathrm{~kJ} \mathrm{~mol}^{-1}\right)$ of the two values (61.5 and $46.4 \mathrm{~kJ} \mathrm{~mol}^{-1}$ ) obtained for $E_{\text {app }}$ by UV-vis, ${ }^{23,24}$ and time resolved XANES $\left(E_{\mathrm{app}}=55.8 \mathrm{~kJ} \mathrm{~mol}^{-1}\right)$ at the LBS are in very good agreement.

What Fig. 3 and 4 show, in a very graphic manner, is that attempting to interrogate this system in a meaningful manner

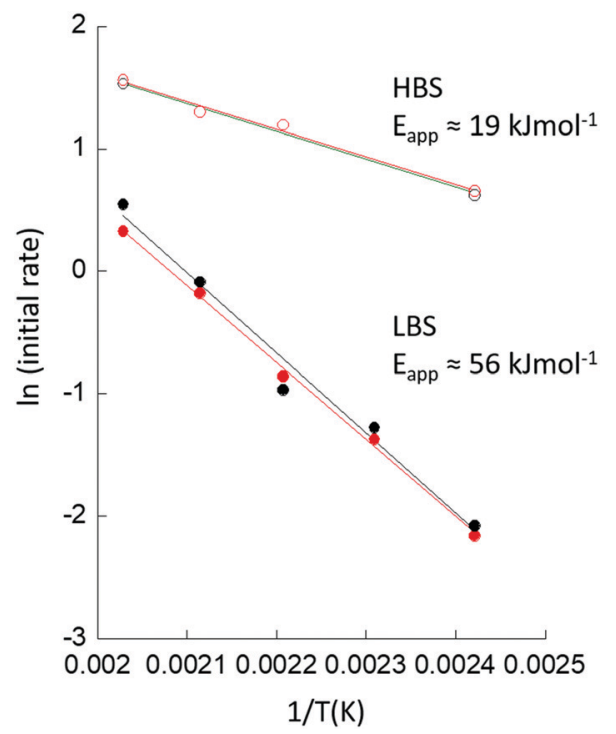

Fig. 4 Arrhenius plots for the reaction of activated Cu/MOR with methane derived from time resolved $\mathrm{Cu} \mathrm{K}$-edge XAFS experiments on activated Cu/MOR at BM31 (LBS, filled circles) and SuperXAS (HBS, open circles), as indicated. In each case, the two sets of data given correspond to derivations of rates based upon the consumption of $\mathrm{Cu}^{\prime \prime}$ or the formation of $\mathrm{Cu}^{\prime}$. The apparent activation energy for the reaction ( $E_{\mathrm{app}}$ ) derived from experimentation using the two beamline is also given. using a "standard" $\left(80 \times 80 \mu^{2}\right.$ focused X-ray beam, brilliance ca. $7-8 \times 10^{13}$ photons $\mathrm{mm}^{-2} \mathrm{~s}^{-1}$ ) is, to varying degrees, a thankless exercise.

The comparative results obtained from this study show that a considerable misrepresentation of the behavior of the $\mathrm{Cu} / \mathrm{MOR}$ at numerous levels may be arrived at when using a (nominally standard) focused X-ray beam at the HBS. As such, any deductions regarding the copper speciation and structures present, which might be derived from subsequent analysis of either the XANES or the EXAFS, must be regarded as highly questionable, as their true provenance cannot be verified using this optical setup. At the LBS, however, the above strongly suggests that when the non-focused X-ray beam is used, it is the chemistry that is inherent to the material that is being observed, and we can go on to derive QSARS that are valid.

\section{Systematic study of the effects of X-ray throughput and brilliance upon the kinetic behaviour of activated Cu/MOR with methane}

Having ascertained that in these $\mathrm{Cu}^{\mathrm{II}}$ containing systems, a significant and unwanted propensity for $\mathrm{Cu}^{\mathrm{II}}$ to be reduced to $\mathrm{Cu}^{\mathrm{I}}$ in the presence of a focused high flux X-ray beam exists, we have undertaken a systematic study of how the photon flux/ brilliance of the HBS is required to be moderated such that meaningful results may be obtained. For this, we have used the reaction of methane with activated $\mathrm{Cu} / \mathrm{MOR}$, as given in Fig. 3, in the knowledge that, with a good degree of confidence, the kinetic results obtained from the LBS are indeed a reliable descriptor of the true behavior of the material.

Fig. 5 shows the results of an LCA analysis of time resolved $\mathrm{Cu}$ K-edge XANES obtained on the HBS for the reaction of high temperature activated ( $723 \mathrm{~K}$ in $20 \mathrm{ml} \mathrm{min}^{-1}$ oxygen) $\mathrm{Cu} / \mathrm{MOR}$ with methane $\left(20 \mathrm{ml} \mathrm{min}^{-1}, 1 \mathrm{bar}\right)$ at $413 \mathrm{~K}$ for the different applied X-ray beams. The pitch and bending of the toroid is used to generate difference beam sizes (i.e. brilliance, vertical $\times$ horizontal in $\mu \mathrm{m}^{2}$, as indicated) to which may be added attenuation of the total photon throughput using carbon attenuators (either $2 \mathrm{~mm}$ or $5 \mathrm{~mm}$ of vitreous carbon, again as indicated). As before, the LCA analysis uses internally derived standards representative of dehydrated $\mathrm{Cu}^{\mathrm{II}}$ and $\mathrm{Cu}^{\mathrm{I}} \cdot{ }^{47-49}$

These data reveal the extent to which the applied photon flux/brilliance affects the apparent degree and rates of reaction of the activated $\mathrm{Cu} / \mathrm{MOR}$ with methane. Fig. 6 quantities aspects of the derived behavior in terms of: (a), the fraction of $\mathrm{Cu}^{\mathrm{I}}$ observed to be present a $t=0$ (i.e. immediately after the switch to a methane feed); (b), the variation in the initial rate of formation of $\mathrm{Cu}^{\mathrm{I}}$, or consumption of $\mathrm{Cu}^{\mathrm{II}}$; and (c), the extent of reaction achieved after 300 seconds of reaction with methane at $413 \mathrm{~K}$.

The apparent behavior of the $\mathrm{Cu} / \mathrm{MOR}$, in terms of the presence or otherwise of $\mathrm{Cu}^{\mathrm{I}}$ at $t=0$, the rates of reaction of the copper with methane, and the overall extent of reaction achieved, are a strong function of the applied X-ray dose. Using a "standard" optical setup (i.e. no attenuation and focal dimensions of $c a . v=80 \times h=80 \mu \mathrm{m}^{2}$ ), as much as $10-15 \%$ of the $\mathrm{Cu}^{\mathrm{II}}$ initially present can be observed to have been converted to $\mathrm{Cu}^{\mathrm{I}}$ 
(a) Cu" using the Cu/MOR sample.

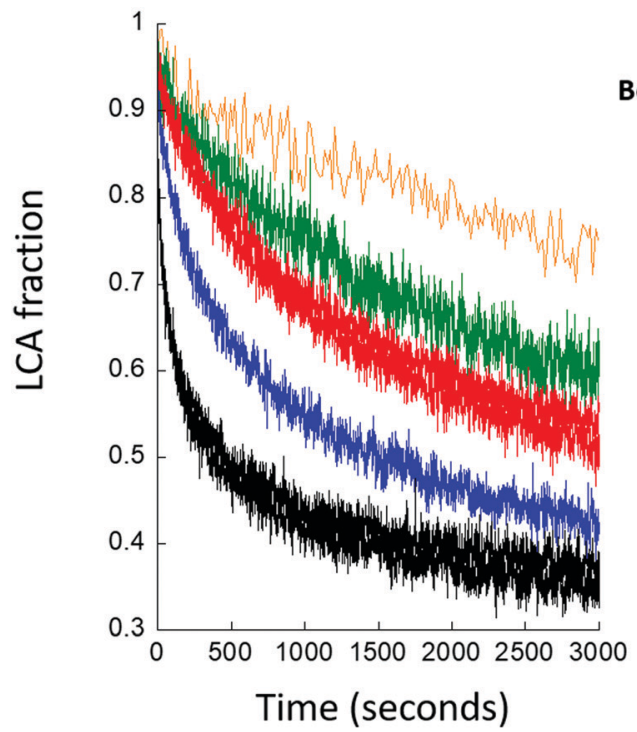

(b) $\mathrm{Cu}^{\prime}$

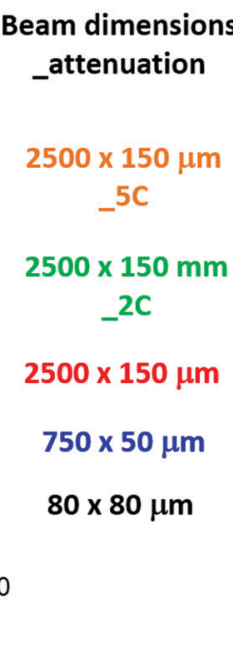

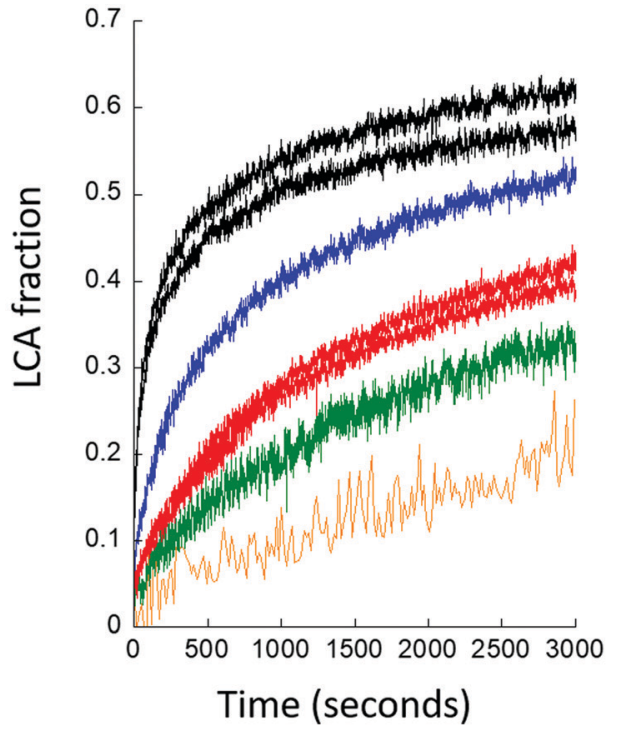

Fig. 5 LCA fractions of (a) $\mathrm{Cu}^{\prime \prime}$ and (b) $\mathrm{Cu}^{\prime}$ extracted from time resolved $\mathrm{Cu}$ K-edge XAFS measured for the reaction of activated Cu/MOR with flowing methane at $413 \mathrm{~K}$ as a function of time and (as indicated) the dimensions of the beam focus applied, along with any attenuation used ( $\_2 \mathrm{C}=2 \mathrm{~mm}$ carbon, $-5 \mathrm{C}=5 \mathrm{~mm}$ carbon). Two sets of data are given for reactions conducted using a fully focused beam ( $80 \times 80 \mu \mathrm{m}^{2}$, black) and a defocused beam $\left(2500 \times 150 \mu \mathrm{m}^{2}\right.$, red). Those for fully focused beam were recorded at the start and end of the investigation; those for the defocused beam, before and after the experiments that utilized a carbon filter. These experimental repetitions serve to verify the level of reproducibility of reactive cycling achieved

under the argon purge ( $c a .300$ seconds in duration before the switch to methane), which is required when switching between pure oxygen and pure methane flows. This adventitious production of $\mathrm{Cu}^{\mathrm{I}}$ is described to a reasonable degree as a logarithmic function of the instantaneous X-ray dose applied (Fig. 6(a)). (see also ESI, $†$ Fig. S2). Equally, the apparent rates of production of $\mathrm{Cu}^{\mathrm{I}}$ and consumption of $\mathrm{Cu}^{\mathrm{II}}$ during the reaction of methane also vary with the instantaneously applied X-ray dose. In this case, however, the dependence of the logarithm of the rate of $\mathrm{Cu}^{\mathrm{I}}$ formation scales with the logarithm of the instantaneously applied power density (Fig. 6(b)). Lastly, we observe that the overall extent of the reaction with methane, that is to say the levels of $\mathrm{Cu}^{\mathrm{I}}$ and $\mathrm{Cu}^{\mathrm{II}}$ achieved after 3000 seconds of exposure at $413 \mathrm{~K}$, also shows a logarithmic dependence upon the instantaneous X-ray dose. We note that in Fig. 6(b), between relative X-ray doses of $c a$. 1/250 or 1/1650 of the un-attenuated and fully focused X-ray beam, the apparent rates, but not the extent of reaction (Fig. 6(c)), become independent of the X-ray (a) Cu' present at $\mathrm{t}=0$

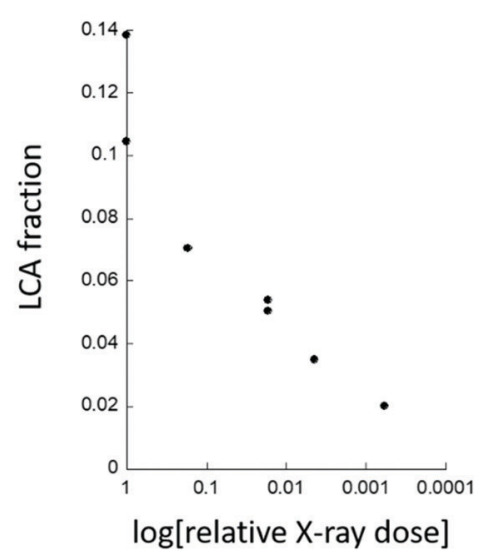

(b) Initial rates of reaction

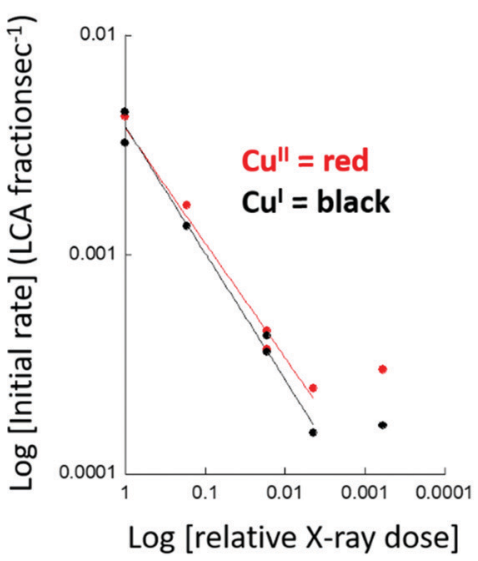

(c) End Cu' and Cull concentrations

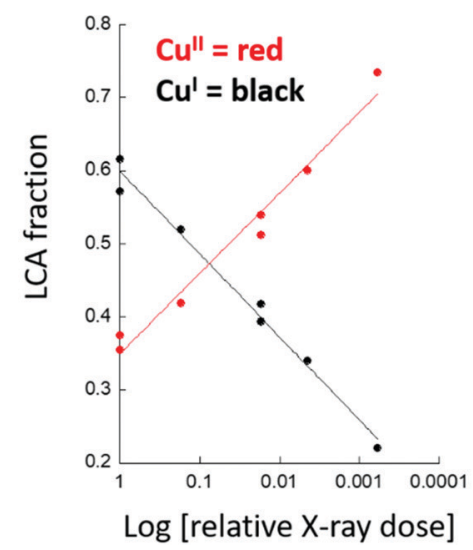

Fig. 6 (a) Dependence of the fraction of $\mathrm{Cu}^{\prime}$ found to be present in $\mathrm{Cu} / \mathrm{MOR}$ at $t=0$ during reactive switching between $20 \mathrm{ml} \mathrm{min}^{-1}$ argon and $20 \mathrm{ml} \mathrm{min}{ }^{-1}$ methane as a function of the logarithm of the applied relative X-ray dose. (b) Logarithm of the initial rates of formation of Cu' (red) and consumption of Cu" (black) as a function of the logarithm of the instantaneous X-ray dose. (c) The levels of Cu' (red) and Cu" (black) achieved after 3000 seconds of reaction in methane at $413 \mathrm{~K}$ versus logarithm of the applied $\mathrm{X}$-ray dose. 


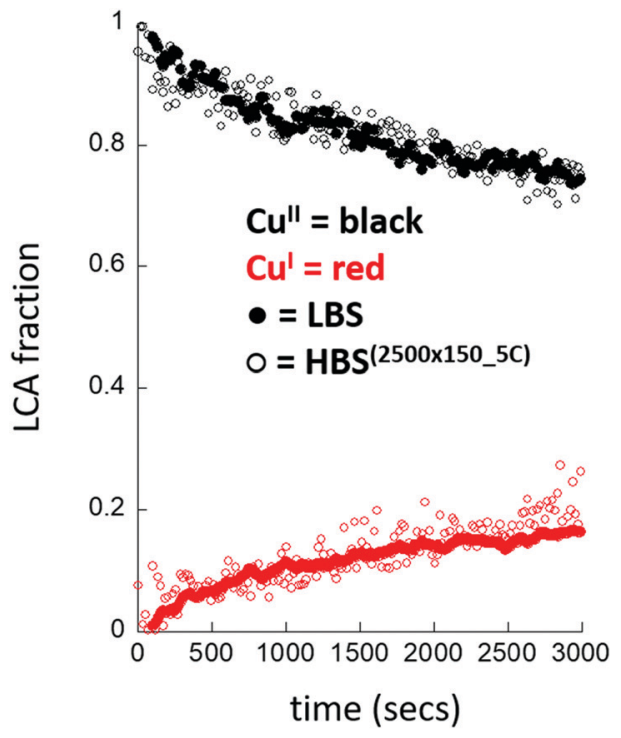

Fig. 7 Comparison of the reaction of activated Cu/MOR $\left(\mathrm{Cu}^{\prime \prime}\right.$ - black symbols, $\mathrm{Cu}^{\prime}$, red symbols) with methane at $413 \mathrm{~K}$ made at the LBS - filled symbols - with that achieved at the HBS (open symbols), after defocusing the $X$-ray beam to dimensions of $2500 \times 150 \mu \mathrm{m}^{2}$, and attenuating the total flux using $5 \mathrm{~mm}$ vitreous carbon before the monochromator. The total decrease in the instantaneous $\mathrm{X}$-ray dose achieved through these modifications is of the order of $1.65 \times 10^{3}$ relative to the unattenuated $80 \times 80 \mu \mathrm{m}^{2}$ "standard" beam.

dose. This indicates that we have arrived close to the point wherein the X-rays themselves are no longer influencing the behavior of the material, and that the degrees and rates of change in the copper observed in this regime of X-ray dose are now close to those that pertain to the intrinsic behaviour of the $\mathrm{Cu} / \mathrm{MOR}$.

Fig. 7 then compares the results obtained at the HBS, using the lowest instantaneous X-ray dose achieved, with the result obtained at the non-focusing LBS at the ESRF using the same experimental setup and conditions. The behaviour of the $\mathrm{Cu} / \mathrm{MOR}$ system is now found to be very similar in each case.

\section{Discussion}

The data and analyses given above demonstrate that, for the two classes of $\mathrm{Cu}^{\mathrm{II}}$ containing materials, the application of $\mathrm{X}$-rays to their study using XAS cannot be assumed to return results that are indicative of the behavior of those materials.

The fact that X-rays, along with other probes, such as electrons and lasers, carry with them a potential for affecting the apparent behavior of materials, either through thermal effects, or through the effects of the secondary production of electrons, resulting from their application, is well known. ${ }^{2-19}$ Furthermore, a propensity for $\mathrm{Cu}^{\mathrm{II}}$ to be reduced to $\mathrm{Cu}^{\mathrm{I}}$ under the influence of X-ray beams has been demonstrated previously, and found to be a function of the nature of counter ions present in homogeneous (aqueous) systems. ${ }^{13,19}$ However, and in spite of many previous X-ray spectroscopic studies of the behaviour of copper containing zeolites for the direct conversion of methane to methanol, ${ }^{26,27,29,31,35,41,42,45-52}$ we are unaware of any previous consideration that the results may have been influenced by the application of the X-ray probe. The results we have obtained show that some good degree of circumspection needs to be applied to the study of these types of material if one is to reliably access the chemistry intrinsic to the material. We have shown that both the apparent degrees and rates of reaction of activated $\mathrm{Cu} / \mathrm{MOR}$ with methane can be influenced by the intensity of the applied X-ray beam. In $\mathrm{Cu} / \mathrm{MOR}$ (and, indeed, $\mathrm{Cu} / \mathrm{MAZ}$, see ESI $\dagger$ ) the adverse effects incurred through the use of power densities that are too high, are very significant. Indeed, in respect of the primary aim of studies such as these, which is to understand the kinetic and speciative behaviour intrinsic to the material, they are terminal. From Fig. 6(b) the initial rates of reaction with methane as a function of instantaneous X-ray dose can be described via a power law (1) i.e.

$$
\mathrm{d}\left[\mathrm{Cu}^{\mathrm{I}}\right] / \mathrm{d} t=k[\mathrm{Cu}]^{a x}
$$

where $t=$ time, $x=$ the X-ray dose, and $0.4<a<0.5$.

As to the source of the highly significant effects that the focusing of the X-ray beam has on various aspects of the kinetics and speciation observed in these systems, we can ascertain that they are very much dependent upon both the applied X-ray flux and the environment that these materials are experiencing. We might further speculate that these unwanted effects, and the extent of their influence, depends upon the composition and structure of the materials investigated. That said, we have equally shown that, through systematic defocusing within the bounds permitted by the optical elements, and then attenuation of the total photon throughput, we can arrive at a situation where X-rays no longer appear to influence the behavior of the material under study.

However, to arrive at this situation a price (over factor of 1000 in terms of flux density) has to be paid in total X-ray brilliance. Very significant reductions in both total photon flux ( $5 \mathrm{~mm}$ of carbon at $9 \mathrm{keV}$ results in only $3.5 \%$ transmission of the X-rays), and overall brilliance (from an optically optimal value of $c a .7-8 \times 10^{13}$ photons $\mathrm{mm}^{-2} \mathrm{~s}^{-1}$ down to $c a .7 \times 10^{10}$ photons $\mathrm{mm}^{-2} \mathrm{~s}^{-1}$ ), are, in these cases, required to be achieved at the HBS, whereas at the LBS no remedial action is required to be taken.

This is important as, in the last ten to fifteen years, trends in both synchrotron and beamline design have consistently pushed up applied power densities. Upgrades (that are ongoing) to the synchrotrons have achieved progressively more coherent and brilliant sources; the use of insertion devices such as wiggler and undulators, that are significantly more powerful than the bending magnet sources used in this study, are commonplace; and, lastly, the use of focusing elements, such as toroidal mirrors, has become almost ubiquitous.

Indeed, it is the case that the vast majority of operational $\mathrm{X}$-ray spectroscopy resources use a combination of all the above mentioned brilliance-enhancing methods. As a result, beamlines that do nothing to increase the brilliance of their X-rays are, nowadays, the exception. $\neq$ This being the case, our results suggest that, for a potentially very broad spectrum of materials 
and methods, the experimental neutrality of the X-rays emanating from many of these sources, should not be taken for granted.

\section{Conclusions}

We have demonstrated that, for two classes of $\mathrm{Cu}^{\mathrm{II}}$ containing materials - surface grafted compounds supported on alumina or silica, and copper-exchanged zeolites - the power densities commonly applied at modern X-ray spectroscopy resources that actively focus their X-rays, have the capacity to affect, in a deleterious manner, the results obtained from a measurement. In the former case, rapid reduction of the $\mathrm{Cu}^{\mathrm{II}}$ present to form $\mathrm{Cu}^{\mathrm{I}}$ renders the structural study of the starting $\mathrm{Cu}^{\mathrm{II}}$ materials impossible using a standard beamline optical setup, as they degrade before a measurement can be completed. In the latter case, the starting state of the material may also be altered, through the same conversion of $\mathrm{Cu}^{\mathrm{II}}$ to $\mathrm{Cu}^{\mathrm{I}}$, before the reaction desired to be studied (in this case, the reaction of activated $\mathrm{Cu}^{\mathrm{II}}$ centres with methane) has commenced. Once the reactive chemistry starts, we have further found that both the overall extent of reaction and the velocity of the reaction can be considerably enhanced by the presence of the X-rays. The experiment, therefore, no longer reports solely upon the chemical reactivity intrinsic to the material. As a result, and in a variety of ways, completely misleading views of how this material functions can therefore result.

However, both these unwanted circumstances can be ameliorated through the application of X-rays of a significantly reduced brilliance. At LBS lines, wherein no focusing elements are employed, the full X-ray flux of the lines may be applied to the sample, and no remedial action need be employed to study these materials in a meaningful way. At more brilliant, focusing resources the same endpoint can be attained; but only through significant defocusing and attenuation of the applied X-ray beam. The reduction in overall applied power density required to for this to be achieved, in the current case, we estimate to be of the order of 1500 compared to what might be considered as a standard operational setup for this beamline.

We can but speculate as to how many different types of materials and situations might suffer from similar dependencies, in terms of the X-ray power densities that may be applied before the materials, and their behaviour, may be affected, and the results drawn from such experimentation become, entirely misleading and invalid.

The results we have obtained, therefore suggest that a good degree of circumspection should be applied in respect of the use of focused X-ray sources in many research areas. Furthermore, if a given experiment may be conducted without recourse to focusing the high fluxes typical of modern X-ray resources, then the safest option would be to use a non-focused X-ray beam if such a situation can be arrived at. Alternatively, a systematic investigation of the materials/conditions to be used, should be entered into prior to any study, in order to establish whether or not, and under what conditions of illumination, the X-rays may be safely and reliably used to obtain accurate information regarding the behaviour of the materials in question.

\section{Conflicts of interest}

There are no conflicts to declare.

\section{Acknowledgements}

We would like to thank SuperXAS beamline, at the Swiss Light Source (SLS) and, Swiss-Norwegian beamlines (SNBL, BM31) at the European Synchrotron radiation Facility (ESRF), Grenoble, France, for access to facilities. MAN and JM would like to acknowledge Shell Global Solutions International B.V. for the funding of their positions. Professor Christophe Copéret (ETH) is acknowledged for his supervision of JM and critical reading and discussion of this manuscript prior to submission.

\section{References}

1 See, for instance (a) X-ray absorption and X-ray emission spectroscopy: theory and applications, ed. J. A. van Bokhoven, and C. Lamberti, Wiley-Blackwell, 2015; (b) XAFS techniques for catalysts, nanomaterials, and surfaces, ed. Y. Iwasawa, K. Asakura and M. Tada, Springer, 2018.

2 E. F. Garman, Radiation damage in macromolecular crystallography: what is it and why should we care?, Acta Crystallogr., Sect. D: Biol. Crystallogr., 2010, 66, 339-351.

3 R. L. Owen, E. Rudino-Pinera and E. F. Garman, Experimental determination of the radiation dose limit for cryocooled protein crystals, Proc. Natl. Acad. Sci. U. S. A., 2006, 103, 4912-4917.

4 J. M. Holton, A beginner's guide to radiation damage, J. Synchrotron Radiat., 2009, 16, 133-142.

5 K. S. Paithankar, R. L. Owen and E. F. Garman, Absorbed dose calculations for macromolecular crystals: improvements to RADDOSE, J. Synchrotron Radiat., 2009, 16, 152-162.

6 A. Meents, S. Gutmann, A. Wagner and C. Schulze-Briese, Origin and temperature dependence of radiation damage in biological samples at cryogenic temperatures, Proc. Natl. Acad. Sci. U. S. A., 2010, 107, 1094-1099.

7 E. De la Mora, J. E. Lovett, C. F. Blanford, E. F. Garman and B. Valderrama, Rudino-Pinera, Structural changes caused by radiation-induced reduction and radiolysis: the effect of X-ray absorbed dose in a fungal multicopper oxidase, Acta Crystallogr., Sect. D: Biol. Crystallogr., 2012, 68, 564-577.

8 H. Serrano-Posada, S. Centeno-Leija, S. P. Rojas-Trjo, C. Rodriguez-Almazan, V. Stojanoff and E. Rudino-Pinera, $\mathrm{X}$-ray-induced catalytic active-site reduction of a multicopper oxidase: structural insights into the proton-relay mechanism and O-2-reduction states, Acta Crystallogr., Sect. D: Biol. Crystallogr., 2015, 71, 2396-2411.

9 S. Horrell, S. V. Antonyuk, R. R. Eady, S. S. Hasnain, M. A. Hough and R. W. Strange, Serial crystallography captures enzyme catalysis in copper nitrite reductase at atomic resolution from one crystal, IUCrJ, 2016, 3, 271-281. 
10 C. Grundahl Frankaer, S. Mossin, K. Stahl and P. Harris, Towards accurate structural characterization of metal centres in protein crystals: the structures of $\mathrm{Ni}$ and $\mathrm{Cu} \mathrm{T} 6$ bovine insulin derivatives, Acta Crystallogr., Sect. D: Biol. Crystallogr., 2014, D70, 110-122.

11 G. N. George, I. J. Pickering, M. J. Pushie, K. Nienaber, M. J. Hackett, I. Ascone, B. Hedman, K. O. Hodgson, J. B. Aitken, A. Levina, C. Glover and P. A. Lay, X-ray-induced photochemistry and X-ray absorption spectroscopy of biological samples, J. Synchrotron Radiat., 2012, 19, 875-886.

12 Y. V. Butenko, L. Alves, A. C. Brieva, J. Yang, S. Krishnamurthy and L. Siller, X-ray induced decomposition of gold nitride, Chem. Phys. Lett., 2006, 430, 89-92.

13 G. J. Mesu, A. M. Beale, F. M. F. de Groot and B. M. Weckhuysen, Probing the influence of X-rays on aqueous copper solutions using time-resolved in situ combined video/X-ray absorption near-edge/ultraviolet-visible spectroscopy, J. Phys. Chem. B, 2006, 110, 17671-17677.

14 A. Plech, V. Kotaidis, A. Siems and M. Sztucki, Kinetics of the X-ray induced gold nanoparticle synthesis, Phys. Chem. Chem. Phys., 2008, 10, 3888-3894.

15 S. H. Chang, J. Kim, C. Phatak, K. D’Aquila, S. K. Kim, J. Kim., S. J. Song, C. S. Hwang, J. A. Eastman and J. W. Freeland, X-ray irradiation induced reversible resistance change in Pt/TiO2/Pt cells, ACS Nano, 2014, 8, 1584-1589.

16 P. Jiang, S. Porsgaard, F. Borondics, M. Kober, A. Caballero, H. Bluhm, F. Besenbacher and M. Salmeron, RoomTemperature Reaction of Oxygen with Gold: An In situ Ambient-Pressure X-ray Photoelectron Spectroscopy Investigation, J. Am. Chem. Soc., 2010, 132, 2858-2859.

17 V. Martis, S. Nikitenko, S. Sen, G. Sankar, W. van Beek, Y. Flinichuk, I. Snigireva and W. Bras, Effects of X-rays on Crystal Nucleation in Lithium Disilicate, Cryst. Growth Des., 2011, 11, 2858-2865.

18 H. B. Stanley, D. Banerjee, L. van Breeman, J. Ciston, C. H. Liebscher, V. Martis, D. H. Merino, A. Longo, P. Pattison and G. W. M. Peters, X-ray irradiation induced reduction and nanoclustering of lead in borosilicate glass, CrystEngComm, 2014, 16, 9331-9339.

19 V. I. Feldman, A. A. Zezin, S. S. Abramchuk and E. A. Zezina, $\mathrm{X}$-ray induced formation of metal nanoparticles from interpolyelectrolyte complexes with copper and silver Ions: The radiationchemical contrast, J. Phys. Chem. C, 2013, 117, 7286-7293.

20 J. Meyet, K. Searles, M. A. Newton, M. Worle, A. P. van Bavel, A. D. Horton, J. A. van Bokhoven and C. Coperet, Monomeric Copper(II) Sites Supported on Alumina Selectively Convert Methane to Methanol, Angew. Chem., Int. Ed., 2019, 58, 9841-9845.

21 M. H. Groothaert, P. J. Smeets, B. F. Sels, P. A. Jacobs and R. A. Schoonheydt, Selective Oxidation of Methane by the Bis( $\mu$-oxo)dicopper Core Stabilized on ZSM-5 and Mordenite Zeolites, J. Am. Chem. Soc., 2005, 127, 1394-1395.

22 P. J. Smeets, M. H. Groothaert and R. A. Schoonheydt, Cu based zeolites: A UV-vis study of the active site in the selective methane oxidation at low temperatures, Catal. Today, 2005, 110, 303-309.
23 J. S. Woertink, P. J. Smeets, M. H. Groothaert, M. A. Vance, B. F. Sels, R. A. Schoonheydt and E. I. Solomon, A [Cu2O $] 2+$ core in Cu-ZSM-5, the active site in the oxidation of methane to methanol, Proc. Natl. Acad. Sci. U. S. A., 2009, 106, 18908-18913.

24 P. Vanelderen, B. E. R. Snyder, M.-L. Tsai, R. G. Hadt, J. Vancauwenbergh, O. Coussens, R. A. Schoonhedyt, B. F. Sels and E. I. Solomon, Spectroscopic definition of the copper active sites in mordenite: selective methane oxidation, J. Am. Chem. Soc., 2015, 137, 6383-6392.

25 E. M. C. Alayon, M. Nachtegaal, M. Ranocchiari and J. A. van Bokhoven, Catalytic conversion of methane to methanol over Cu-mordenite, Chem. Commun., 2012, 48, 404-406.

26 E. M. C. Alayon, M. Nachtegaal, E. Kleymenov and J. A. van Bokhoven, Determination of the electronic and geometric structure of $\mathrm{Cu}$ sites during methane conversion over $\mathrm{Cu}$ MOR with X-ray absorption spectroscopy, Microporous Mesoporous Mater., 2013, 166, 131-136.

27 E. M. C. Alayon, M. Nachtegaal, A. Bodi and J. A. van Bokhoven, Reaction Conditions of Methane-to-Methanol Conversion Affect the Structure of Active Copper Sites, ACS Catal., 2014, 4, 16-22.

28 G. Li, P. Vassilev, M. Sanchez-Sanchez, J. A. Lercher, E. M. C. Hensen and E. A. Pidko, Stability and reactivity of copper oxo-clusters in ZSM-5 zeolite for selective methane oxidation to methanol, J. Catal., 2016, 338, 305-312.

29 S. Grundner, M. A. C. Markovits, G. Li, M. Tromp, E. A. Pidko, E. J. M. Hensen, A. Jentys, M. Sanchez-Sanchez and J. A. Lercher, Single-site trinuclear copper oxygen clusters in mordenite for selective conversion of methane to methanol, Nat. Commun., 2015, 6, 7546.

30 M. J. Wulfers, S. Teketel, B. Ipek and R. F. Lobo, Conversion of methane to methanol on copper-containing small-pore zeolites and zeotypes, Chem. Commun., 2015, 51, 4447-4450.

31 E. M. C. Alayon, M. Nachtegaal, A. Bodi, M. Ranocchiari and J. A. van Bokhoven, Bis( $\mu$-oxo) versus mono( $\mu$-oxo)dicopper cores in a zeolite for converting methane to methanol: an in situ XAS and DFT investigation, Phys. Chem. Chem. Phys., 2015, 17, 7681-7693.

32 S. Grundner, W. Luo, M. Sanchez-Sanchez and J. A. Lercher, Synthesis of single-site copper catalysts for methane partial oxidation, Chem. Commun., 2016, 52, 2553-2556.

33 P. Tomkins, A. Mansouri, S. E. Bozbag, F. Krumeich, M. B. Park, E. M. C. Alayon, M. Ranocchiari and J. A. van Bokhoven, Isothermal cyclic conversion of methane into methanol over copper-exchanged zeolite at lowtemperature, Angew. Chem., Int. Ed., 2016, 55, 5557-5561.

34 P. Tomkins, M. Ranocchiari and J. A. van Bokhoven, Direct Conversion of methane to methanol under mild conditions over Cu-Zeolites and beyond, Acc. Chem. Res., 2017, 50, 418-425.

35 S. E. Bozbag, E. M. C. Alayon, J. Pecháček, M. Nachtegaal, M. Ranocchiari and J. A. van Bokhoven, Methane to methanol over copper mordenite: yield improvement through multiple cycles and different synthesis techniques, Catal. Sci. Technol., 2016, 6, 5011-5022. 
36 A. R. Kulkarni, Z. J. Zhao, S. Siahrostami, J. K. Norskov and F. Studt, Theoretical Insights into the selective oxidation of methane to methanol in copper-exchanged mordenite, ACS Catal., 2016, 6, 6531-6536.

37 K. Narsimhan, K. Iyoki, K. Dinh and Y. Román-Leshkov, catalytic oxidation of methane into methanol over copperexchanged Zeolites with Oxygen at Low Temperature, ACS Cent. Sci., 2016, 2, 424-429.

38 S. H. Lee, J. K. Kang and E. D. Park, Continuous methanol synthesis directly from methane and steam over $\mathrm{Cu}$ (II)exchanged mordenite, Korean J. Chem. Eng., 2018, 35, 2145-2149.

39 B. Ipek, M. J. Wulfers, H. Kim, F. Göltl, I. Hermans, J. P. Smith, K. S. Booksh, C. M. Brown and R. F. Lobo, Formation of $\left[\mathrm{Cu}_{2} \mathrm{O}_{2}\right]^{2+}$ and $\left[\mathrm{Cu}_{2} \mathrm{O}\right]^{2+}$ toward $\mathrm{C}-\mathrm{H}$ Bond Activation in Cu-SSZ13 and Cu-SSZ-39, ACS Catal., 2017, 7, 4291-4303.

40 D. Palagin, A. J. Knorpp, A. B. Pinar, M. Ranocchiari and J. A. van Bokhoven, Assessing the relative stability of copper oxide clusters as active sites of a CuMOR zeolite for methane to methanol conversion: size matters?, Nanoscale, 2017, 9, 1144-1153.

41 V. L. Sushkevich, D. Palagin, M. Ranocchiari and J. A. van Bokhoven, Selective anaerobic oxidation of methane enables direct synthesis of methanol, Science, 2017, 356, 523-527.

42 D. K. Pappas, E. Borfecchia, M. Dyballa, I. A. Pankin, K. A. Lomachenko, A. Martini, M. Signorile, S. Teketel, B. Arstad, G. Berlier, C. Lamberti, S. Bordiga, U. Olsbye, K. P. Lillerud, S. Svelle and P. Beato, Methane to Methanol: Structure-Activity Relationships for Cu-CHA, J. Am. Chem. Soc., 2017, 139, 14961-14975.

43 M. B. Park, S. H. Ahn, A. Mansouri, M. Ranocchiari and J. A. van Bokhoven, Comparative study of diverse copper zeolites for the conversion of methane into methanol, ChemCatChem, 2017, 9, 3705-3713.

44 A. R. Kulkarni, Z. J. Zhao, S. Siahrostami, J. K. Norskov and F. Studt, Cation-exchanged zeolites for the selective oxidation of methane to methanol, Catal. Sci. Technol., 2018, 8, 114-123.

45 V. L. Sushkevich, D. Palagin and J. A. van Bokhoven, The effect of the active-site structure on the activity of copper mordenite in the aerobic and anaerobic conversion of methane into methanol, Angew. Chem., Int. Ed., 2018, 57, 8906-8910.

46 V. L. Sushkevich, D. Palagin and J. A. van Bokhoven, Effect of Brønsted acid sites on the direct conversion of methane into methanol over copper-exchanged mordenite, Catal. Sci. Technol., 2018, 16, 4141-4150.

47 M. A. Newton, A. J. Knorpp, A. B. Pinar, V. L. Sushkevich, D. Palagin and J. A. van Bokhoven, On the mechanism underlying the direct conversion of methane to methanol by copper hosted in zeolites; braiding $\mathrm{Cu}$ K-Edge XANES and reactivity Studies, J. Am. Chem. Soc., 2018, 140, 10090-10093.

48 A. J. Knorpp, M. A. Newton, A. B. Pinar and J. A. van Bokhoven, Conversion of methane to methanol on copper mordenite: redox mechanism of isothermal and hightemperature-activation procedures, Ind. Eng. Chem. Res., 2018, 57, 12036-12039.

49 A. J. Knorpp, A. B. Pinar, M. A. Newton, V. L. Sushkevich and J. A. van Bokhoven, Copper-exchanged omega (MAZ) zeolite: copper-concentration dependent active sites and its unprecedented methane to methanol conversion, ChemCatChem, 2018, 10, 5593-5596.

50 D. K. Pappas, A. Martini, M. Dyballa, K. Kvande, S. Teketel, K. A. Lomachenko, R. Baran, P. Glatzel, B. Arstad, G. Berlier, C. Lamberti, S. Bordiga, U. Olsbye, S. Svelle, P. Beato and E. Borfecchia, The nuclearity of the active site for methane to methanol conversion in Cu-mordenite: a quantitative assessment, J. Am. Chem. Soc., 2018, 140, 15270-15278.

51 B. E. R. Snyder, P. Vanelderen, R. A. Schoonheydt, B. F. Sels and E. I. Solomon, Second-sphere effects on methane hydroxylation in Cu-Zeolites, J. Am. Chem. Soc., 2018, 140, 9236-9243.

52 G. Brezicki, J. D. Kammert, T. B. Gunnoe, C. Paolucci and R. J. Davis, Insights into the speciation of $\mathrm{Cu}$ in the $\mathrm{Cu}-\mathrm{H}-$ mordenite catalyst for the oxidation of methane to methanol, ACS Catal., 2019, 9, 5308-5319.

53 J.-P. Lange, K. P. de Jong, J. Ansorge and P. J. A. Tijm, Keys to methane conversion technologies, Stud. Surf. Sci. Catal., 1997, 107, 81-86.

54 M. Ahlquist, R. J. Nielsen, R. A. Periana and W. A. Goddard, Product protection, the key to developing high performance methane selective oxidation catalysts, J. Am. Chem. Soc., 2009, 131, 17110-17115.

55 M. Ravi, M. Ranocchiari and J. A. van Bokhoven, The direct catalytic oxidation of methane to methanol-A critical assessment, Angew. Chem., Int. Ed., 2017, 56, 16464-16483.

56 W. Van Beek, O. V. Safonova, G. Wiker and H. Emerich, SNBL, A dedicated beamline for combined in situ X-ray diffraction, X-ray absorption and Raman scattering experiments, Phase Transitions, 2011, 84, 726-732.

57 O. Mueller, M. Nachtegaal, J. Just, D. Lutxenkirchen-Hecht and R. Frahm, Quick-EXAFS setup at the SuperXAS beamline for in situ X-ray absorption spectroscopy with $10 \mathrm{~ms}$ time resolution, J. Synchrotron Radiat., 2016, 23, 260-266.

58 Center for X-Ray Optics, http://henke.lbl.gov/optical_con stants/filter2.html.

59 P. J. Chupas, K. W. Chapman, C. Kurtz, J. C. Hanson, P. L. Lee and C. P. Grey, A versatile sample-environment cell for non-ambient X-ray scattering experiments, J. Appl. Crystallogr., 2008, 41, 822-824.

60 M. A. Newton, A. J. Knorpp, D. Stoian, W. van Beek, H. Emerich, A. Longo, S. Checchia and J. A. van Bokhoven, On isothermality in some commonly used plug flow reactors for X-ray based investigations of catalysts, Catal. Sci. Technol., 2019, 9, 3081-3089.

61 S. J. A. Figueroa and C. Prestipino, PrestoPronto: a code devoted to handling large data sets, J. Phys.: Conf. Ser., 2016, 712, 012012.

62 A. H. Clark, J. Imbao, R. Frahm and M. Nachtegaal, ProQEXAFS: a highly optimized parallelized rapid processing 
software for QEXAFS data, J. Synchrotron Rad., 2020, 27, 551-557.

63 P. A. Jacobs, W. D. Wilde, R. A. Schoonheydt, J. B. Uytterhoeven and $\mathrm{H}$. Beyer, Redox behaviour of transition-metal ions in zeolites, 3. Auto-reductions of cupric ions in $\mathrm{Y}$ zeolites, J. Chem. Soc., Faraday Trans., 1976, 72, 1221-1230.

64 J. Sarkany, Effect of water on the autoreduction level of copper in excessively ion-exchanged Cu/ZSM-5. An FTIR study, J. Mol. Struct., 1997, 410, 137-140.

65 C. Dossi, A. Fusi, G. Moretti, S. Recchia and R. Psaro, On the role of carbonaceous material in the reduction of $\mathrm{Cu}^{2+}$ to $\mathrm{Cu}^{+}$in Cu-ZSM-5 catalysts, Appl. Catal., A, 1999, 188, 107-119.

66 F. X. L. I. Xamena, P. Fisicaro, G. Berlier, A. Zecchina, G. T. Palomino, C. Prestipino, S. Bordiga, E. Giamello and C. Lamberti, Thermal reduction of $\mathrm{Cu}^{2+}$-mordenite and Reoxidation upon interaction with $\mathrm{H}_{2} \mathrm{O}, \mathrm{O}_{2}$, and NO, J. Phys. Chem. B, 2003, 107, 7036-7044.

67 F. Amano, T. Tanaka and T. Funabiki, Auto-reduction of $\mathrm{Cu}(\mathrm{II})$ species supported on $\mathrm{Al}_{2} \mathrm{O}_{3}$ to $\mathrm{Cu}(\mathrm{I})$ by thermovacuum treatment, J. Mol. Catal. A: Chem., 2004, 221, 89-95.

68 V. L. Sushkevich and J. A. van Bokhoven, Revisiting copper reduction in zeolites: the impact of autoreduction and sample synthesis procedure, Chem. Commun., 2018, 54, 7447-7450.

69 V. L. Sushkevich, A. V. Simomov and J. A. van Bokhoven, Autoreduction of copper in zeolites: role of topology, $\mathrm{Si} / \mathrm{Al}$ ratio, and copper Loading, J. Phys. Chem. C, 2019, 123, 9926-9934.
70 A. Di Cicco, G. Aquilanti, M. Minicucci, E. Principi, N. Novello, A. Cognigni and L. Olivi, Novel XAFS capabilities at ELETTRA synchrotron light source, J. Phys.: Conf. Ser., 2009, 190, 012043.

71 A. J. Dent, G. Cibin, S. Ramos, A. D. Smith, S. M. Scott, L. Varandas, M. R. pearson, N. A. Krumpa, C. P. Jones and P. E. Robbins, B18: A core XAS spectroscopy beamline for Diamond, J. Phys.: Conf. Ser., 2009, 190, 012039.

72 V. Briois, C. La Fontaine, S. Belon, L. Barthe, T. Moreno, V. Pinty, A. Carcy, R. Giradot and E. Fonda, ROCK: the new Quick-EXAFS beamline at SOLEIL, J. Phys.: Conf. Ser., 2016, 712, 012149.

73 C. La Fontaine, L. Barthe, A. Rochet and V. Briois, X-ray absorption spectroscopy and heterogeneous catalysis: Performances at the SOLEIL's SAMBA beamline, Catal. Today, 2013, 205, 148-158.

74 K. Klementiev, K. Noren, S. Carlson, C. K. G. V. Sigfridsson and I. Persson, The BALDER Beamline at the MAX IV Laboratory, J. Phys.: Conf. Ser., 2016, 712, 012023.

75 L. Simonelli, C. Marini, W. Olszewski, M. A. Perez, N. Ramanan, G. Guilera, V. Cuatero and K. Klementiev, CLAESS: The hard X-ray absorption beamline of the ALBA CELLS synchrotron, Cogent Phys., 2016, 3, 1231987.

76 W. A. Caliebe, V. Murzin, A. Kalinko and M. Goelitz, HighFlux XAFS-Beamline P64 at PETRA III, AIP Conf. Proc., 2019, 2054, 060031.

77 E. Welter, R. Chermikov, M. Herrmann and R. Nemusat, A beamline for bulk sample X-ray absorption spectroscopy at the high brilliance storage ring PETRA III, AIP Conf. Proc., 2019, 2054, 040002. 